\title{
Incorporação de lodo da estação de tratamento de esgoto (ETE) em cerâmica vermelha
}

\section{(Incorporation of sludge of the sewage treatment station (STS) into red ceramic)}

\author{
I. O. R. Areias, C. M. F. Vieira, R. da S. T. Manhães, A. C. Intorne \\ Universidade Estadual do Norte Fluminense Darcy Ribeiro, Av. Alberto Lamego 2000, \\ Campos dos Goytacazes, RJ, 28013-602 \\ oraisabela@gmail.com,vieira@uenf.br,rosane.toledo@gmail.com,aline_intorne@yahoo.com.br
}

\begin{abstract}
Resumo
Este trabalho teve por objetivo avaliar a incorporação de resíduo de estação de tratamento de esgoto (ETE) na produção de cerâmica vermelha. As matérias-primas utilizadas foram: massa cerâmica argilosa e resíduo de ETE provenientes do município de Campos dos Goytacazes - RJ. As matérias-primas foram caracterizadas pelas técnicas de fluorescência de raios X e difração de raios $\mathrm{X}$; além disso, foi determinada a área de superfície específica das mesmas por meio das técnicas de BET e azul de metileno. O comportamento térmico do resíduo de ETE foi avaliado por meio de análise termogravimétrica. Formulações foram preparadas com $0,2,5,10$ e $15 \%$ em massa de resíduo de ETE incorporados à massa argilosa. Corpos de prova foram confeccionados por prensagem uniaxial a $20 \mathrm{MPa}$ com $8 \%$ de umidade para calcinação a $950{ }^{\circ} \mathrm{C}$. As propriedades físicas e mecânicas avaliadas das cerâmicas calcinadas foram retração linear, absorção de água e resistência à compressão. A microestrutura destas peças foi investigada com auxílio de microscopia eletrônica de varredura. Os resultados indicaram que este tipo de resíduo deve ser incorporado em pequenas quantidades (até $2,5 \%$ ) para não prejudicar as propriedades físicas e mecânicas da cerâmica.

Palavras-chave: resíduo de ETE, reciclagem, cerâmica vermelha.
\end{abstract}

\begin{abstract}
This study aimed to evaluate the waste incorporation of sewage treatment station (STS) on the production of red ceramic. The used raw materials were clayey ceramic body and STS waste from Campos dos Goytacazes - RJ. The raw materials were characterized through techniques of X-ray fluorescence and X-ray diffraction; moreover, the specific surface area was determined by means of the BET and blue methylene techniques. The thermal behavior of STS waste was evaluated by thermal gravimetric analysis. Formulations were prepared with 0, 2.5, 10 and $15 \mathrm{wt} \%$ STS waste in the clayey ceramic. Specimens were prepared by uniaxial pressing at $20 \mathrm{MPa}$ with $8 \%$ moisture content and calcination at $950{ }^{\circ} \mathrm{C}$. The evaluated physical and mechanical properties of the calcined ceramics were water absorption and compression strength. The microstructure of calcined pieces was investigated by scanning electron microscopy. The results showed that this type of waste must be incorporated in low amounts (up to 2.5 wt\%) to avoid deleterious effects on the ceramic physical and mechanical properties.
\end{abstract}

Keywords: STS waste, recycling, red ceramic.

\section{INTRODUÇÃO}

O lodo de esgoto tem um alto potencial de riscos à saúde pública, ao ambiente e à proliferação de vetores de moléstias e organismos nocivos [1]. O lodo de estação de tratamento de esgoto (ETE) gera uma grande quantidade de resíduo devido a restos metabólicos do homem que não se desintegram com o tratamento [2]. A característica do lodo de ETE é resultante do tratamento a que é submetido que pode ser químico, físico e/ou biológico [3]. A causa para o aumento da produção de resíduos sólidos gerados pelo homem e dos danos provocados ao meio ambiente está na falta de políticas gerenciais, tecnologias de reuso e educação ambiental que levem à disposição adequada dos mesmos [4].
Dentre as principais formas de disposição do lodo de ETE se destacam a incineração, disposição em aterros sanitários e uso agrícola. Em países da Europa e da América do Norte, o lodo de tratamento de esgoto geralmente é incinerado e depositado em aterros sanitários ou utilizado em áreas agrícolas. No Brasil, é comum o lodo de ETE ser descartado em lixões a céu aberto ou em aterros sanitários. Trabalhos vêm sendo feitos para modificar esta situação a partir de ações preventivas de redução e reciclagem.

A reciclagem destes materiais é de grande interesse para as indústrias, principalmente devido às exigências dos órgãos ambientais. Uma das práticas estudadas para destinação correta destes resíduos tem sido a utilização em materiais da construção civil, como blocos de vedação e telhas à base 
de argilas. A variabilidade natural das características das argilas associada a técnicas de processamento relativamente simples e ainda a baixa performance exigida para os produtos permitem a presença de níveis de impurezas relativamente elevados. Desta forma é possível incorporar outros tipos de materiais resultantes das mais diversas fontes de geração, como podem ser percebidos nas pesquisas que são reportadas a reciclagem de resíduos [5-7]. A indústria cerâmica tem se destacado nos últimos anos como uma alternativa promissora para o destino de grandes quantidades de resíduos sólidos poluentes de diversos tipos e origens [512], quando comparada aos métodos tradicionais. Além do mais, as características físico-químicas das matérias-primas, bem como seu processamento, favorecem a incorporação de resíduos na massa cerâmica. Vale destacar que para o processo produtivo, a incorporação pode ser vantajosa, uma vez que reduz o consumo de matérias-primas e de energia, consequentemente reduz os custos de produção [7]. Desta maneira, o uso de resíduos como matéria-prima para o setor cerâmico se aplica como uma destinação correta e reciclagem do resíduo, evitando a ocorrência de áreas degradadas assim como diminuindo o consumo de matérias-primas do meio ambiente, uma vez que uma das matérias-primas mais utilizada na produção de cerâmica é a argila [12]. Resultados da incorporação do lodo de ETE à cerâmica vermelha vêm apontando ser uma alternativa eficiente e definitiva $[9,10$, $12,13]$, porque o processo de vitrificação utilizado torna inertes os contaminantes presentes no resíduo, evitando a lixiviação destes para o meio ambiente [11].

O município de Campos dos Goytacazes localiza-se na região norte do estado do Rio de Janeiro, Brasil, com uma população estimada de 480 mil habitantes. No município, há seis estações de tratamento de esgoto que são responsáveis pelo tratamento de cerca de $70 \%$ dos esgotos gerados, produzindo 160 ton/mês de lodo. Quanto ao setor cerâmico, esta região possui um papel importante na produção de cerâmica, com 120 indústrias, gerando uma produção de cerca de 60 milhões de peças/mês, entre tijolos, lajotas, ladrilhos rústicos e uma pequena parte de telhas, entre outros, respondendo por aproximadamente cinco mil empregos diretos [14]. Nesta pesquisa, o objetivo do estudo foi investigar a possibilidade da incorporação do lodo de ETE no desenvolvimento de cerâmica vermelha, visando o aproveitamento do resíduo na região norte do estado do Rio de Janeiro. O uso do lodo de ETE para este tipo de trabalho tem potencial de acarretar economia de energia e a conservação de recursos naturais, diminuindo o uso de matéria-prima natural, além de propiciar um destino ambientalmente correto para este resíduo.

\section{MATERIAIS E MÉTODOS}

As matérias-primas utilizadas neste estudo foram uma massa cerâmica composta por argilas cauliníticas da região de Campos dos Goytacazes, estado do Rio de Janeiro, Brasil, e lodo de ETE proveniente da Concessionária Águas do Paraíba, Estação de Tratamento de Esgoto de Chatuba, localizada no município de Campos dos Goytacazes, RJ.
Este tipo de tratamento envolve reator anaeróbio de fluxo ascendente (RAFA), anóxico, biodrum, decantadores secundário e terciário. O lodo de ETE foi submetido ao processo de inertização com hidróxido de cálcio, cal hidratada calcítica da Supercal, 15\% em massa, para eliminar microrganismos patogênicos. É um reagente fortemente alcalino e normalmente de preço reduzido, utilizado em diversas atividades relacionadas com a preservação das condições sanitárias e da higiene nas grandes e pequenas comunidades. Com a alcalinidade da cal que transmite ao meio em que é adicionada, a maioria dos microrganismos não encontra um meio adequado para o seu crescimento e sobrevivência e, assim, o ambiente fica desinfectado e livre de maus odores.

Após a coleta do material na estação de tratamento, uma amostra foi retirada para realizar o teste de umidade em laboratório. Primeiramente a amostra crua, de lodo ainda não inertizado, foi pesada retirando uma pequena quantidade para a medição do $\mathrm{pH}$. Posteriormente, a amostra foi colocada em estufa a $65^{\circ} \mathrm{C}$ por $48 \mathrm{~h}$. Após esse período, a umidade do lodo foi de $77 \%$. A partir desse resultado foi calculada a quantidade de hidróxido de cálcio (cal) utilizada para a caleação. A concentração mais adequada ao proposto foi o uso de $15 \%$ da cal em relação ao lodo seco. Deste modo, o $\mathrm{pH}$ se manteria próximo de 12 por $2 \mathrm{~h}$ ou 11,5 por $48 \mathrm{~h}$ após a aplicação, como preconiza o Conselho Nacional do Meio Ambiente (CONAMA) [1, 15]. Após esta aplicação, o pH do resíduo de esgoto se apresentou numa média de 12,15, satisfazendo a preconização do CONAMA $[1,15]$. Em seguida, as matérias-primas foram secas em estufa de laboratório a $110^{\circ} \mathrm{C}$ até massa constante.

A análise química elementar das matérias-primas foi obtida por fluorescência de raios X (FRX) com equipamento da Philips, PW 2400. A análise de difração de raios X (DRX) foi realizada em um difratômetro Rigaku, Ultima IV, utilizando radiação monocromática de $\mathrm{CuK} \alpha$, com varredura de 3 a $75^{\circ}$, passo de $0,02^{\circ}$ por 3 s. A capacidade de troca catiônica, CTC, e a área de superfície específica, SE, total do lodo de ETE e da massa cerâmica foram obtidas pela técnica azul de metileno, AM; esta foi utilizada, por sua rapidez, simplicidade e reprodutibilidade. Esta metodologia baseia-se no fato de que o azul de metileno $\left[\mathrm{C}_{16} \mathrm{H}_{18} \mathrm{ClN}_{3} \mathrm{~S}\left(3 \mathrm{H}_{2} \mathrm{O}\right)\right]$, quando em solução aquosa ou etanólica e em contato com materiais carregados negativamente, tem suas moléculas absorvidas rapidamente, devido a um mecanismo de troca iônica irreversível. À medida que as posições de troca vão sendo preenchidas, a velocidade de absorção decresce, devido ao tamanho do cátion. $\mathrm{O}$ ensaio consistiu na titulação de uma suspensão do material a ser ensaiado, cujo pH se manteve neutro, com uma solução de azul de metileno. A capacidade de troca catiônica foi obtida pela seguinte expressão:

$$
\mathrm{CTC}=\frac{\mathrm{C}_{\mathrm{MBT}} \times \mathrm{V}_{\mathrm{MBT}} \times 100}{\mathrm{Wa}}
$$

onde, $\mathrm{C}_{\mathrm{MBT}}$ é concentração do azul de metileno, $\mathrm{V}_{\mathrm{MBT}}$ é o volume gasto do azul de metileno e Wa é a massa da 
amostra seca corrigida. A área de superfície específica em $\mathrm{m}^{2} / \mathrm{g}$ foi calculada a partir do volume gasto para saturar a superfície da amostra, ou seja, o volume absorvido pelos minerais argilosos. O fator que converte a CTC em superfície específica é igual a 7,8043 e está relacionado com as dimensões da molécula de azul de metileno:

$$
\mathrm{SE}=\text { fator de conversão } \times \mathrm{CTC}
$$

A área de superfície específica externa da massa cerâmica também foi determinada pela técnica Brunauer, Emmett e Teller, BET, com adsorção de $\mathrm{N}_{2}$ a $-195,85{ }^{\circ} \mathrm{C}$, sendo a amostra desgaseificada automaticamente a $22{ }^{\circ} \mathrm{C}$ durante $5 \mathrm{~h}$. O equipamento utilizado foi da Micrometrics, ASAP 2020C. O comportamento térmico do resíduo de ETE foi avaliado por análise termogravimétrica, TG (TA Instruments, SDT 2960), na faixa de 0 a $800{ }^{\circ} \mathrm{C}$, com uma taxa de aquecimento de $10^{\circ} \mathrm{C} / \mathrm{min}$, com atmosfera de $\mathrm{N}_{2}$.

Quatro formulações foram preparadas: 0, 2,5, 10 e $15 \%$ em massa do lodo de ETE incorporados na massa cerâmica. Foram confeccionados 7 corpos de prova de formato retangular, $115 \mathrm{~mm} \times 25 \mathrm{~mm} \times 10 \mathrm{~mm}$, com $8 \%$ de umidade, conformados por prensagem uniaxial a $20 \mathrm{MPa}$ para cada formulação. Em seguida os corpos de prova foram secos em estufa a $110{ }^{\circ} \mathrm{C}$ até massa constante e posteriormente calcinados a $950{ }^{\circ} \mathrm{C} \mathrm{em}$ forno laboratorial tipo mufla, com taxa de aquecimento de $2{ }^{\circ} \mathrm{C} / \mathrm{min}$, até atingir a temperatura de patamar, mantida por $120 \mathrm{~min}$. O resfriamento foi realizado por convecção natural, desligando-se o forno. As propriedades tecnológicas investigadas foram: retração linear, absorção de água e resistência à compressão. A absorção de água foi determinada de acordo com procedimentos estabelecidos por norma [16]. A resistência à compressão foi determinada em uma máquina universal de ensaios (Instron, 5582). Para este ensaio, os corpos de prova tiveram suas dimensões preparadas para $115 \mathrm{~mm} \mathrm{x}$ $2,5 \mathrm{~mm} \times 10 \mathrm{~mm}$. A microestrutura das peças calcinadas foi analisada por MEV. Foi utilizado um microscópio Shimadzu, Superscan SSX500-50.

\section{RESULTADOS E DISCUSSÃO}

Embora o lodo tenha sido submetido ao processo de inertização na estação de tratamento, seu pH aferido após coleta na ETE ficou em torno de 7,66, indicando que o processo de inertização na estação de tratamento não foi eficaz. Após a inertização, uma nova amostra foi coletada para medição do $\mathrm{pH}$, para investigar se estava de acordo com o CONAMA $[1,15]$. A Tabela I apresenta os resultados da medição do pH das amostras após a caleação. Notou-se um valor médio de $\mathrm{pH}$ de 12,15, 7 h após esse procedimento, o qual foi realizado de maneira satisfatória, pois, de acordo com a norma [1, 15], o pH deve estar em 12 por $2 \mathrm{~h}$. Depois da caleação, o lodo foi distribuído em 7 caixas de amianto forradas com plástico, onde permaneceu armazenado até a realização completa dos experimentos.

A Fig. 1a apresenta o difratograma de raios $\mathrm{X}$ do resíduo
Tabela I - Valores de pH do lodo de ETE após inertização/ caleação por 7 ou $24 \mathrm{~h}$.

[Table I - pH values of the STS sludge 7 or $24 \mathrm{~h}$ after inertization process.]

\begin{tabular}{ccc}
\hline $\mathrm{ID}$ & $\mathrm{pH}(7 \mathrm{~h})$ & $\mathrm{pH}(24 \mathrm{~h})$ \\
\hline 1 & 12,14 & 10,68 \\
2 & 12,20 & 11,61 \\
3 & 12,25 & 11,61 \\
4 & 12,07 & 11,50 \\
5 & 12,12 & 11,31 \\
6 & 12,30 & 10,90 \\
7 & 12,01 & 11,13 \\
Média & 12,15 & 11,24 \\
\hline
\end{tabular}

de ETE utilizado nesse trabalho. Destaca-se que o resíduo de ETE foi constituído principalmente de carbonato de cálcio $\left(\mathrm{CaCO}_{3}\right)$, gipsita $\left[\mathrm{Ca}\left(\mathrm{SO}_{4}\right) \cdot 2 \mathrm{H}_{2} \mathrm{O}\right]$, quartzo $\left(\mathrm{SiO}_{2}\right)$ e heterosita $\left(\mathrm{FePO}_{4} \cdot \mathrm{H}_{2} \mathrm{O}\right)$. Outros minerais presentes foram: caulinita $\left[\mathrm{Al}_{2} \mathrm{Si}_{2} \mathrm{O}_{5}(\mathrm{OH})_{4}\right]$, muscovita $\left[\mathrm{KAl}_{2} \mathrm{O}_{10}(\mathrm{OH})_{2}\right]$, e rutilo $\left(\mathrm{TiO}_{2}\right)$. As presenças de $\mathrm{CaCO}_{3}$ e $\mathrm{CaSO}_{4} \cdot 2 \mathrm{H}_{2} \mathrm{O}$, provavelmente, se deram devido ao tratamento que este resíduo recebeu com hidróxido de cálcio (cal hidratada) no processo de desinfecção do lodo na ETE e também do processo de inertização recebido após a coleta, já no laboratório. A presença de $\mathrm{FePO}_{4}$ se deu, possivelmente, devido ao processo de tratamento do tanque aeróbio em que o lodo foi digerido por bactérias aeróbias; neste processo recebeu cloreto férrico para regular alguns parâmetros, como pH e cor. Na Fig. 1b é apresentado o difratograma de raios $\mathrm{X}$ da massa cerâmica. Pôde-se observar que a massa cerâmica foi constituída, sobretudo, de caulinita e quartzo. Foram também identificadas as presenças de albita $\left[\mathrm{Na}\left(\mathrm{AlSi}_{3} \mathrm{O}_{8}\right)\right]$, gibbsita $\left[\mathrm{Al}(\mathrm{OH})_{3}\right]$, muscovita, montmorillonita $\left[(\mathrm{Ca}, \mathrm{Na})_{0.33}(\mathrm{Al}, \mathrm{Mg})_{2}\left(\mathrm{Si}_{4} \mathrm{O}_{10}\right)(\mathrm{OH})_{2} \cdot \mathrm{nH}_{2} \mathrm{O}\right] \mathrm{e}$ ortoclásio $\left[\mathrm{K}\left(\mathrm{AlSi}_{3} \mathrm{O}_{8}\right)\right]$. Estes resultados foram compatíveis com resultados reportados na literatura que abordaram a caracterização mineralógica de argilas e massas argilosas de Campos dos Goytacazes [17-20].

A Tabela II apresenta os resultados da composição química das matérias-primas utilizadas. Pôde-se observar que o resíduo de ETE foi constituído essencialmente por $\mathrm{SiO}_{2}, \mathrm{CaO}, \mathrm{Al}_{2} \mathrm{O}_{3}$ e $\mathrm{Fe}_{2} \mathrm{O}_{3}$, que corresponderam a cerca de 43,65\%, com predominância de sílica e óxido de cálcio. Ainda foi identificada a presença de $\mathrm{P}_{2} \mathrm{O}_{5}, \mathrm{MgO}, \mathrm{K}_{2} \mathrm{O}$ e TiO${ }_{2}$. Todos os compostos detectados estavam presentes no resíduo de ETE associados aos minerais identificados por DRX (Fig. 1a). O resíduo de ETE também apresentou elevada perda ao fogo de 43,57\% em massa; isto se deveu principalmente à oxidação da matéria orgânica, bem como à perda de água de constituição dos argilominerais, desidratação de hidróxidos [21] e liberações decorrentes das alterações estruturais do carbonato [12], da gipsita e heterosita. Esta elevada perda ao fogo pode ser uma desvantagem durante o processo de 

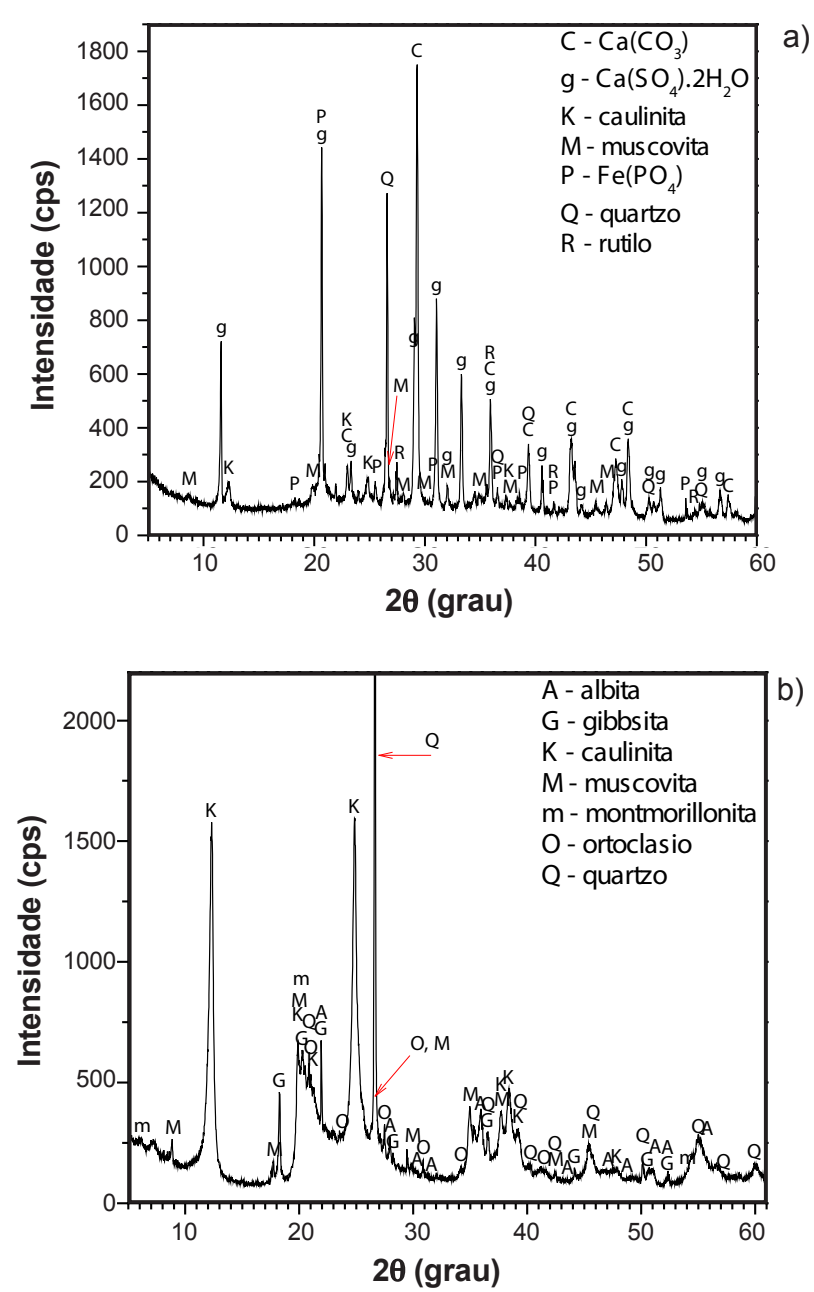

Figura 1: Difratogramas de raios X de: (a) lodo de ETE; (b) massa cerâmica.

[Figure 1: X-ray diffraction patterns of: (a) STS sludge; (b) clayey ceramic.]

queima da cerâmica, devido à possibilidade de aumentar a porosidade da cerâmica assim como a retração excessiva das peças. Na Tabela II também são mostrados os resultados da composição química da massa cerâmica. Notou-se uma constituição predominante de $\mathrm{SiO}_{2}(62,98 \%)$ e $\mathrm{Al}_{2} \mathrm{O}_{3}$ $(21,23 \%)$. A sílica apresentou-se normalmente na forma de sílica livre (quartzo) ou presente nos aluminossilicatos. A alumina, que foi o segundo mais abundante, formou parte da estrutura dos aluminossilicatos identificados (caulinita, montmorillonita, muscovita, albita e ortoclásio) e também da gibbsita. Ainda para a massa cerâmica, observaramse as presenças de $\mathrm{Fe}_{2} \mathrm{O}_{3}, \mathrm{~K}_{2} \mathrm{O}, \mathrm{TiO}_{2}$ e $\mathrm{MgO}$ que podem ocorrer em forma de impurezas e constituição dos minerais micáceos (muscovita) e feldspatos (ortoclásio e albita) identificados por DRX, ressaltando que o óxido de potássio $\left(\mathrm{K}_{2} \mathrm{O}\right)$ participou diretamente na formação da muscovita e do ortoclásio.

A partir dos resultados obtidos do ensaio de CTC, foi determinada a área de superfície específica (SE) total das matérias-primas através da Equação B. A Tabela III apresenta os valores da CTC e da SE total das matérias-primas, bem como a SE externa da massa cerâmica. Verificou-se que o lodo de ETE apresentou valor de CTC de 48,60 meq/100 $\mathrm{g}$ e a massa cerâmica de $13,50 \mathrm{meq} / 100 \mathrm{~g}$. Notou-se que os valores de SE total pelo método azul de metileno para o lodo de ETE foi de $379,3 \mathrm{~m}^{2} / \mathrm{g}$ e para a massa cerâmica $105,4 \mathrm{~m}^{2} / \mathrm{g}$. Foi determinado ainda o valor de $20,00 \mathrm{~m}^{2} / \mathrm{g}$ da SE externa, pelo método de BET, para a massa cerâmica. O valor determinado é esperado para esse tipo de material [22, 23]. Observou-se que o valor da SE total pela técnica AM do resíduo apresentou maior valor em comparação com a massa cerâmica; este fato ocorre quando o material apresenta maior concentração de matéria orgânica assim como maiores teores de óxidos de ferro [22], como é o caso do lodo de ETE conforme identificado na Tabela II.

A curva termogravimétrica do lodo de ETE é apresentada na Fig. 2. Observaram-se quatro eventos térmicos em 53,9, $126,288,1$ e $619,4^{\circ} \mathrm{C}$, acompanhados por uma significativa perda de massa na amostra do resíduo estudado. Houve uma perda de massa inicial de 5,0\%, ocorrendo entre 25 e $120{ }^{\circ} \mathrm{C}$, aproximadamente, associada à perda de água de umidade. Entre 120 e $150{ }^{\circ} \mathrm{C}$ teve uma perda de massa de $2,7 \%$, referente à perda de água fisicamente adsorvida [12]. Em $288,1{ }^{\circ} \mathrm{C}$ ocorreu a maior perda de massa, $34,2 \%$ (entre 140 e $575^{\circ} \mathrm{C}$, aproximadamente), atribuída à decomposição da matéria orgânica [12], desidratação e decomposição da gipsita e da heterosita [24, 25], bem como pela queima do

Tabela II - Composições químicas (\% em massa) do lodo de ETE e da massa cerâmica.

[Table II - Chemical compositions (wt\%) of STS sludge and clayey ceramic.]

\begin{tabular}{ccc}
\hline Óxido & ETE & Massa cerâmica \\
\hline $\mathrm{Al}_{2} \mathrm{O}_{3}$ & 8,83 & 21,23 \\
$\mathrm{SiO}_{2}$ & 14,26 & 62,98 \\
$\mathrm{Fe}_{2} \mathrm{O}_{3}$ & 7,78 & 2,73 \\
$\mathrm{~K}_{2} \mathrm{O}$ & 0,71 & 1,21 \\
$\mathrm{MgO}$ & 0,76 & 0,48 \\
$\mathrm{MnO}$ & $<0,05$ & $<0,05$ \\
$\mathrm{Na} 2$ & 0,19 & 0,38 \\
$\mathrm{CaO}$ & 12,78 & 0,35 \\
$\mathrm{P}_{2} \mathrm{O}_{5}$ & 2,04 & 0,08 \\
$\mathrm{TiO}_{2}$ & 0,63 & 0,89 \\
$\mathrm{BaO}$ & $<0,1$ & $<0,1$ \\
$\mathrm{Co}_{2} \mathrm{O}_{3}$ & $<0,1$ & $<0,1$ \\
$\mathrm{Cr}_{2} \mathrm{O}_{3}$ & $<0,1$ & $<0,1$ \\
$\mathrm{PbO}_{20}$ & $<0,1$ & $<0,1$ \\
$\mathrm{SrO}$ & $<0,1$ & 0,07 \\
$\mathrm{ZnO}$ & 0,11 & $<0,1$ \\
$\mathrm{ZrO}_{2}+\mathrm{HfO}$ & $<0,1$ & $<0,1$ \\
$\mathrm{PF}$ & 43,57 & 9,47 \\
\hline PF - perda ao fogo & &
\end{tabular}

PF - perda ao fogo. 
Tabela III - Valores de capacidade de troca catiônica (CTC), superfície específica pelos métodos azul de metileno (AM) e BET das matérias-primas utilizadas.

[Table III - Values of cation exchange capacity, specific surface area by blue methylene and BET methods of raw materials used.]

\begin{tabular}{cccc}
\hline Amostra & $\begin{array}{c}\text { CTC } \\
(\mathrm{meq} / 100 \mathrm{~g})\end{array}$ & $\begin{array}{c}\text { Área de superfície específica } \\
\text { total }-\mathrm{AM}\left(\mathrm{m}^{2} / \mathrm{g}\right)\end{array}$ & $\begin{array}{c}\text { Área de superfície específica } \\
\text { externa }-\mathrm{BET}\left(\mathrm{m}^{2} / \mathrm{g}\right)\end{array}$ \\
\hline Lodo de ETE & 48,60 & 379,3 & - \\
Massa cerâmica & 13,50 & 105,4 & 20,00 \\
\hline
\end{tabular}

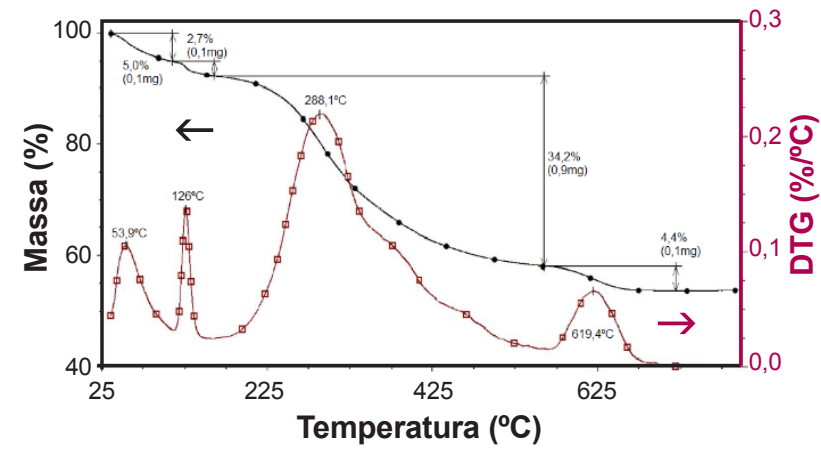

Figura 2: Curvas de análise termogravimétrica do lodo de ETE. [Figure 2: Thermogravimetric curves of the STS sludge.]

carbono e materiais voláteis. Por fim, a $619,4{ }^{\circ} \mathrm{C}$ houve um pico acompanhado da perda de massa de $4,4 \%$, associada à decomposição do carbonato de cálcio presente no lodo, conforme observado na difração de raios X (Fig. 1a) [25].

$\mathrm{Na}$ Fig. 3 são apresentadas as micrografias das cerâmicas com adições de 0 e 2,5\% de lodo de ETE calcinadas a $950{ }^{\circ} \mathrm{C}$. Observou-se que a composição com adição do lodo de ETE apresentou uma textura levemente mais rugosa e com evidência de porosidade, em comparação com as cerâmicas sem adição deste resíduo; possivelmente isto foi devido à incorporação do resíduo que dificultou o empacotamento das partículas e liberou $\mathrm{CO}_{2}$ durante a etapa de calcinação, dando um aspecto mais rugoso à superfície da cerâmica. Essas características adquiridas pela cerâmica na calcinação favorecem a porosidade aberta e consequentemente o aumento da absorção de água, que pode ser prejudicial à cerâmica.

A Fig. 4 apresenta os resultados de retração linear de queima, absorção de água e resistência à compressão das cerâmicas calcinadas a $950{ }^{\circ} \mathrm{C}$. Como mostrado na Fig. 4a, a formulação com $10 \%$ de lodo de ETE apresentou um valor médio de retração linear levemente maior que as demais formulações, possivelmente devido ao menor grau de empacotamento destes corpos de prova durante a etapa de conformação. Era de se esperar um incremento da retração da cerâmica com o teor de lodo de ETE, em função de sua elevada perda de massa durante a etapa de calcinação, como pode ser verificado através da análise termogravimétrica (Fig. 2). Entretanto, atribuiu-se a um eventual aprisionamento de gases provenientes da decomposição de minerais constituintes do resíduo uma expansão da cerâmica que foi suficiente para anular parte da retração. Nota-se na Fig. 4b que para as
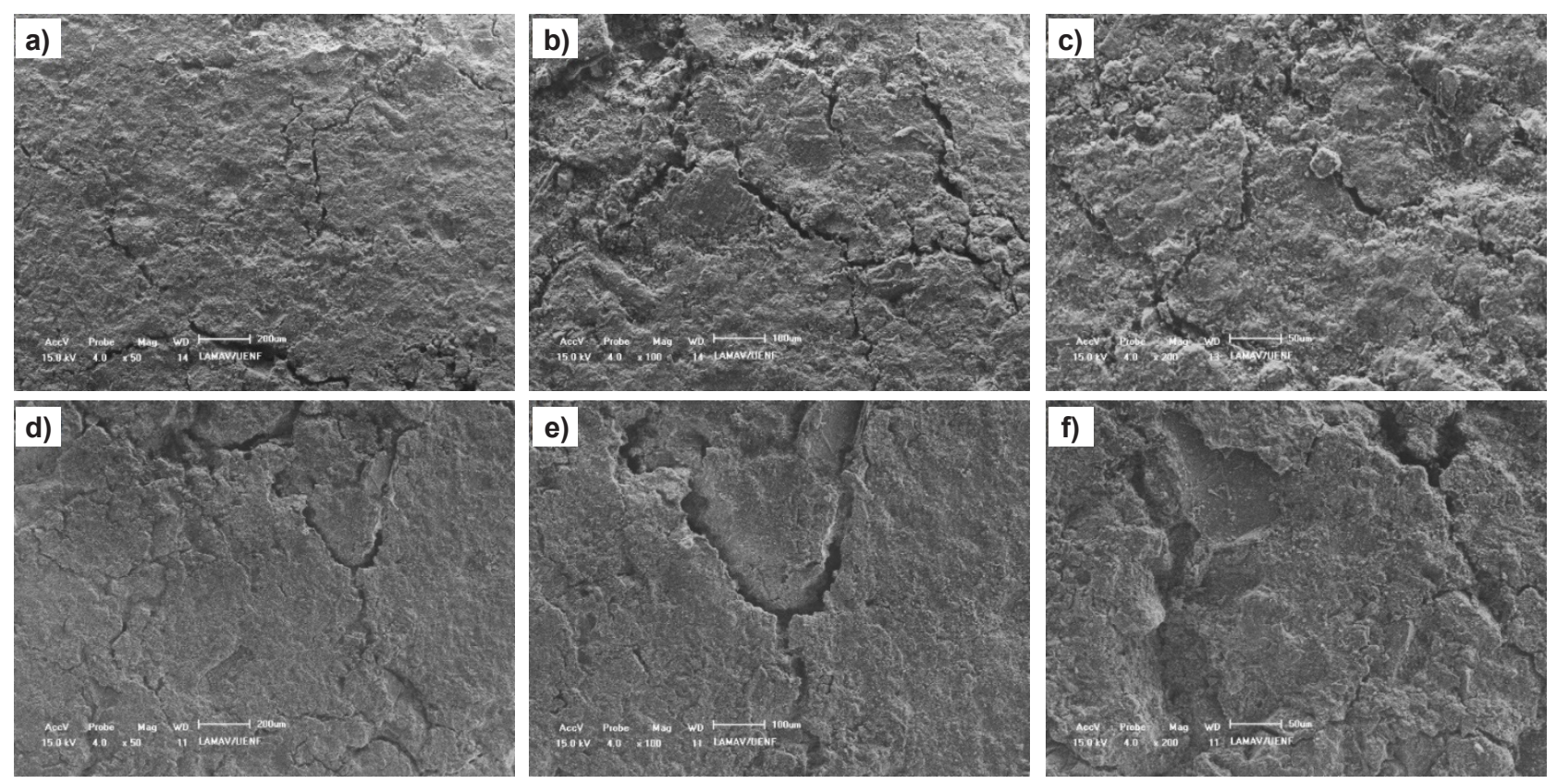

Figura 3: Micrografias obtidas por microscopia eletrônica de varredura das cerâmicas sem adição (a-c) e com adição de $2,5 \%$ de lodo de ETE (d-f), em diferentes aumentos.

[Figure 3: SEM micrographs of the fired ceramics with no addition (a-c) and with 2.5\% of the STS sludge (d-f), with different magnifications.] 
composições utilizadas com a adição de 10 e $15 \%$ do lodo de ETE, a absorção de água aumentou consideravelmente a ponto de extrapolar o limite máximo permitido para blocos de vedação, 22\% [26]. Observou-se ainda que nenhuma cerâmica ficou dentro dos limites indicados para telhas, inferior a 20\% [27]. Isto foi devido, provavelmente, à decomposição e liberações gasosas de alguns constituintes do
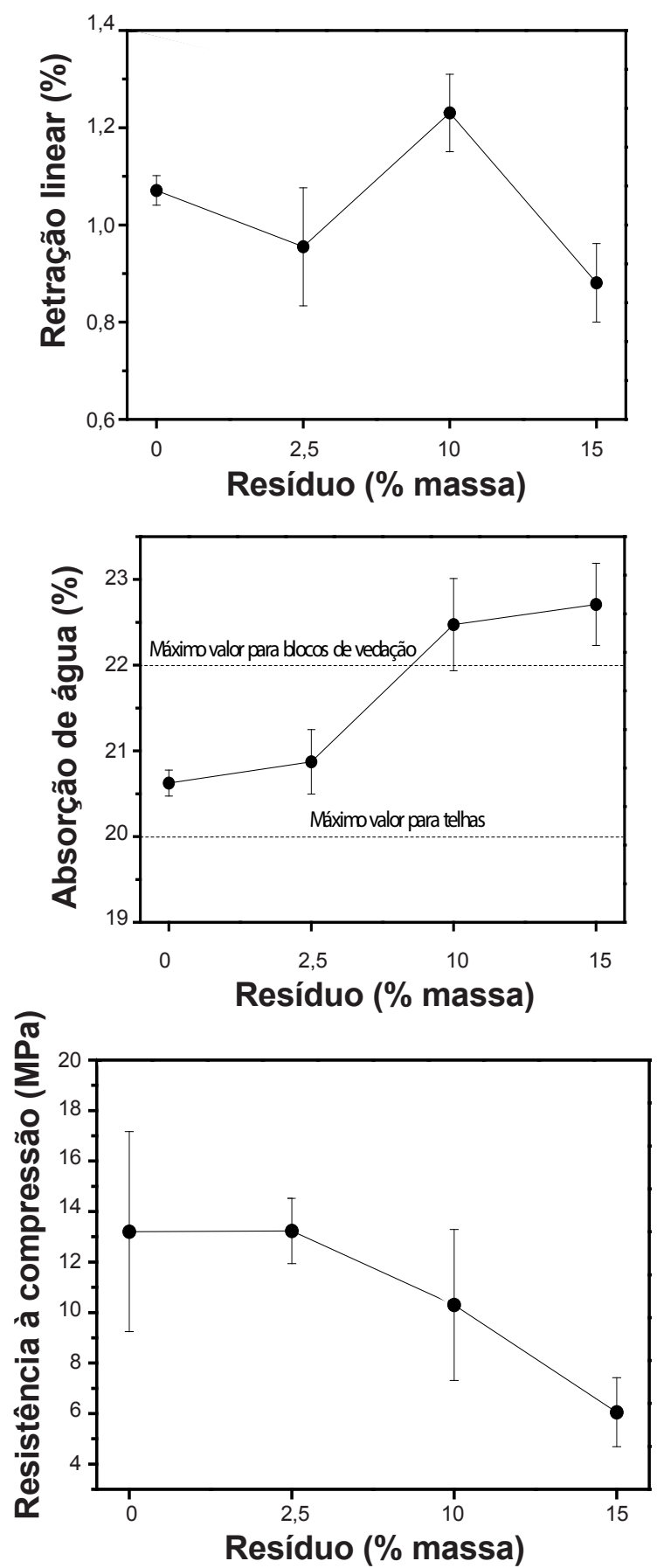

c)

Figura 4: Resultados de retração linear (a), absorção de água (b) e resistência à compressão (c) das cerâmicas calcinadas a $950{ }^{\circ} \mathrm{C}$ em função do teor de resíduo de ETE adicionado.

[Figure 4: Results of linear shrinkage (a), water absorption (b), and compression strength (c) of ceramics calcined at $950{ }^{\circ} \mathrm{C}$ as a function of the added content of STS sludge.] resíduo, como matéria orgânica, carbonato de cálcio, gipsita e heterosita, que aumentaram a porosidade aberta, além de estar associado ao comportamento refratário das argilas de Campos [17, 18, 20, 28, 29]. A Fig. 4c mostra os valores da resistência à compressão das cerâmicas calcinadas a $950{ }^{\circ} \mathrm{C}$. Verificouse uma tendência de redução da resistência mecânica com a incorporação de lodo de ETE, sobretudo com 15\%. Para esta formulação a redução, considerando o valor médio, foi de 65,4\%. A diminuição da resistência mecânica foi devido, provavelmente, ao aumento da porosidade da cerâmica pela combustão da matéria orgânica presente no resíduo e das liberações gasosas citadas anteriormente.

\section{CONCLUSÕES}

O lodo de ETE não vem inertizado da estação de tratamento de maneira eficaz, pois seu $\mathrm{pH}$ aferido, após coleta na ETE, foi em torno de 7,66 e este deveria estar medindo 11,5 por pelo menos $48 \mathrm{~h}$ ou 12 por $2 \mathrm{~h}$, tendo sido necessário inertizá-lo antes de ser incorporado à massa cerâmica. $\mathrm{O}$ resíduo de ETE quimicamente foi constituído principalmente por $\mathrm{SiO}_{2}, \mathrm{CaO}, \mathrm{Al}_{2} \mathrm{O}_{3}$ e $\mathrm{Fe}_{2} \mathrm{O}_{3}$, além da presença de $\mathrm{P}_{2} \mathrm{O}_{5}, \mathrm{MgO}, \mathrm{K}_{2} \mathrm{O}$ e TiO ${ }_{2}$, com predominância de sílica e óxido de cálcio e elevada perda ao fogo $(43,57 \%)$. A massa cerâmica apresentou como compostos majoritários o $\mathrm{Al}_{2} \mathrm{O}_{3}$ e $\mathrm{SiO}_{2}$, além da presença de $\mathrm{Fe}_{2} \mathrm{O}_{3}, \mathrm{~K}_{2} \mathrm{O}, \mathrm{TiO}_{2}$ e $\mathrm{MgO}$, com predominância de sílica $(62,98 \%)$ e perda ao fogo de $9,47 \%$. Do ponto de vista mineralógico, o resíduo de ETE foi constituído principalmente por carbonato de cálcio, gipsita, quartzo e heterosita, tendo também a presença dos minerais caulinita, muscovita e rutilo. A massa cerâmica foi rica em caulinita e quartzo com presença de albita, gibbsita, muscovita, montmorillonita e ortoclásio. A área de superfície específica (SE) pelo método azul de metileno encontrada para o lodo de ETE foi de $379,3 \mathrm{~m}^{2} / \mathrm{g}$ e para a massa cerâmica foi de $105,4 \mathrm{~m}^{2} / \mathrm{g}$. Já a SE externa pelo método de BET para a massa cerâmica foi de $20,00 \mathrm{~m}^{2} / \mathrm{g}$. Os valores obtidos em ambos os métodos foram compatíveis com resultados apresentados na literatura para este tipo de material. Foi constatado que o resíduo de ETE tende a reduzir a resistência à compressão e aumentar a absorção de água, causando superfícies rugosas que sugerem porosidade aberta. Com base nos resultados obtidos, é possível indicar uma destinação final do lodo de ETE como incorporação em cerâmica vermelha. Ressalta-se, no entanto, que a adição deste resíduo à massa cerâmica deve ser realizada em torno de $2,5 \%$ em massa.

\section{AGRADECIMENTOS}

Os autores agradecem ao CNPq, proc. n. 302930/20140, e FAPERJ, proc. n. E-26/201.192/2014, e ainda às acadêmicas Lidiane de Lima Lousada e Thaís Motta Granato.

\section{REFERÊNCIAS}

[1] Cons. Nac. Meio Amb., Resol. n 375/06 (2006). 
[2] W. Bettiol, O.A. de Camargo, "Lodo de esgoto: impactos ambientais na agricultura", Embrapa, Jaguariúna (2006) 17349.

[3] B. Jin, B. Wilen, P. Lant, Chem. Eng. J. 95 (2003) 221234.

[4] P.R.L. Araújo, in Anais Congr. Int. Administr., Ponta Grossa (2010).

[5] M. Dondi, M. Marsigli, B. Fabbri, Tile Brick Int. 13, 3 (1997) 218-225.

[6] C.M.F. Vieira, S.N. Monteiro, Rev. Matéria 14, 3 (2009) 881-905.

[7] R.R. Menezes, G.A. Neves, H.C. Ferreira, Rev. Bras. Eng. Agríc. Ambient. 6 (2002) 303-313.

[8] G.P. Souza, J.N.F. Holanda, Ceram. Int. 30, 1 (2005) 99104.

[9] C.H. Weng, D.F. Lin, P.C. Chiang, Adv. Environ. Res. 7, 203 (2003) 679-685.

[10] J.A. Cusidó, L.V. Cremades, Waste Manage. 32 (2012) 1202-1208.

[11] A.C. Teloeken, D.L. Villanova, T.M. Basegio, C.P. Bergmann, Cerâm. Ind. 16, 2 (2011) 14-19.

[12] C.R.L. da Silva, A.L. Chinelatto, A.S.A. Chinelatto, Cerâmica 61, 357 (2015) 31-40.

[13] Y. Tian, W. Zuo, D. Chen, J. Hazard. Mater. 196 (2011) 370-379.

[14] C.M.F. Vieira, I.O.R. Areias, S.N. Monteiro, "Rewas 2016: towards materials resource sustainability" (2016) 165-170.

[15] Cons. Nac. Meio Amb., Resol. n 380/06 (2006).

[16] Am. Soc. Test. Mater., ASTM C373 (1972).
[17] M.P. Babisk, T.P. Altoé, H.J.O. Lopes, U.S. do Prado, M.C.B. Gadioli, L.L.P. de Almeida, S.N. Monteiro, C.M.F. Vieira, Mater. Sci. Forum 798-799 (2014) 514-519.

[18] C.M.F. Vieira, R.M. Pinheiro, Cerâmica 57, 343 (2011) 319-323.

[19] L.L.P. de Almeida, L.J.T. Petrucci, E.M. Pessanha, L.P. Paixão, F.S. Maia, in Anais $19^{\circ}$ Congr. Bras. Eng. Ciênc. Mater. (2010) 407-413.

[20] C.M.F. Vieira, J.N.F. de Holanda, D.G. Pinatti, Cerâmica 46, 297 (2000) 14-17.

[21] E.M.S. Oliveira, S.Q. Machado, J.N.F. Holanda, Cerâmica 50, 316 (2004) 324-330.

[22] F. Grohmann, Boletim Cient. Inst. Agron. Est. S. Paulo, 3113 (1972) 145-165.

[23] G.C. Cordeiro, J.M. Désir, Cerâmica 56, 337 (2010) 71-76.

[24] D.M. Moore, D.C. Reynolds Jr., X-Ray diffraction and the identification and analysis of clay minerals, $2^{\text {nd }}$ Ed., Oxford Univ. Press, New York (1997) 256-259.

[25] D.N. Todor, Thermal analysis of minerals, Abacus Press, Inglaterra (1976).

[26] Assoc. Bras. Nor. Técn., NBR-15270, Rio de Janeiro (2005).

[27] Assoc. Bras. Nor. Técn., NBR-15310, Rio de Janeiro (2009).

[28] C.M.F. Vieira, T.M. Soares, S.N. Monteiro, Cerâmica 49, 312 (2003) 245-250.

[29] C.M.F. Vieira, L.A. Peçanha Jr., S.N. Monteiro, Cerâmica 52, 322 (2006) 138-145.

(Rec. 03/03/2016, Rev. 25/07/2016, 24/09/2016, 19/12/2016, Ac. 19/12/2016) 